that our patient had melanoma metastatic to the orbit. Although it is rare for a primary orbital melanoma to arise without pre-existing congenital orbital melanocytosis, we believe that the patient reported here does represent a rare example of a primary orbital melanoma arising de novo, without clinical or histopathological evidence of pre-existing orbital melanocytosis or blue naevus.

Extensive necrosis of the central portion of the tumour in our case caused the lesion to have a cystic appearance on CT. The yellow cheesy material encountered at surgery suggested the diagnosis of dermoid cyst. However, orbital dermoid cysts usually occur in children in a superotemporal anterior location and may be attached to bone. ${ }^{22}$ They can occasionally occur in the orbital soft tissues, in which cases they are usually located on the nasal side and are lined by conjunctival epithelium. ${ }^{22-24}$

Based on the clinical findings, histopathological features, and follow up information, we believe that the lesion in our patient represents a highly unusual primary orbital melanoma.

Presented at the 1991 Meeting of the Pan American Ophthalmic Pathology Society, Los Angeles, CA, 11 October 1991.

This work was supported by the Eye Tumor Research Foundation Inc, Philadelphia, PA, the Robert Beckman Endowment Fund, Philadelphia, PA, and the Macula Foundation, New York.

1 Shields JA. Primary melanocytic tumors. In: Shields JA, ed. Diagnosis and management of orbital tumors. Philadelphia: Diagnosis and management

2 Shields JA, Shields CL. Posterior uveal melanoma: clinical and pathologic features. In: Shields JA, Shields CL, eds. Intraocular tumors. A text and atlas. Philadelphia: Saunders, 1992: 117-36.

3 Jakobiec FA, Font RL. Orbit. In: Spencer WH, Font RL, Green WR, Howes EL, Jakobiec FA, Zimmerman LE, eds. Ophthalmic pathology. An atlas and textbook. Philadelphia: Saunders, 1986: 2656-60.
4 Shields JA. Orbital malignant melanomas. In: Hornblass A, ed. Ophthalmic plastic and reconstructive surgery. Baltimore: Williams and Wilkins, 1988: 1048-52.

5 Coppeto JR, Jaffe R, Gillies CG. Primary orbital melanoma. Arch Ophthalmol 1978; 96: 2255-8.

6 Drews RC. Primary malignant melanoma of the orbit in a negro. Arch Ophthalmol 1975; 93: 335-6.

7 Dutton JJ, Anderson RL, Schelper RL, Purcell JJ, Tse DT. Orbital malignant melanoma and oculodermal melanocytosis: report of two cases and review of the literature. Ophthalmology 1984; 91: 497-507.

8 Ellis D, Spencer WH, Stephenson CM. Congenital neurocutaneous melanosis with metastatic orbital malignant melanoma. Ophthalmology 1986; 93: 1639-42.

9 Foster J. An encapsulated orbital melanoma. Br F Ophthalmol 1944; $21: 293-8$.

10 Hagler WS, Brown CC. Malignant melanoma of the orbit arising in a nevus of Ota. Trans Am Acad Ophthalmol arising in a nevus of Ota.
Otolaryngol 1966; 78: 817-22.

11 Haim T, Meyer E, Kerner H, Zonis S. Oculodermal melanocytosis (nevus of Ota) and orbital malignant melanoma. Ann Ophthalmol 1982; 14: 1132-6

12 Henderson JW, Farrow GM. Malignant melanoma primary in the orbit. Report of a case. Trans Am Acad Ophthalmol Otolaryngol 1972; 76: 1487-90.

13 Jakobiec FA, Ellsworth RM, Tannenbaum M. Primary orbital melanoma. Am $\mathcal{f}$ Ophthalmol 1974; 78: 24-39.

14 Jay B. Malignant melanoma of the orbit in a case of oculodermal melanosis (nevus of Ota). Br F Ophthalmol 1965; 49: 359-63.

15 Rottino A, Kelly AS. Primary orbital melanoma. Case report with review of the literature. Arch Ophthalmol 1942;27:934 49.

16 Wilkes SR, Uthman EO, Thornton CN, Cole RE. Malignant melanoma of the orbit in a black patient with ocular melanocytosis. Arch Ophthalmol 1984; 102: 904-6.

17 Wolter JR, Bryson JM, Blackhurst RT. Primary orbital melanoma. Ear Nose Throat $\mathcal{F} 1966 ; 45: 64-7$.

18 Rice CD, Brown HH. Primary orbital melanoma associated with orbital melanocytosis. Arch Ophthalmol 1990; 108: $1130-4$.

19 Shields JA, Bakewell B, Augsberger JJ, Flanagan JC. Classification and incidence of space-occupying lesions of the orbit. A survey of 645 biopsies. Arch Ophthalmol 1984; 102: 1606-11.

20 Henderson JW, Farrow GM. Orbital tumors. 2nd ed. New York: Decker, division of Thieme-Stratton, 1980: 325-43.

21 Leff SR, Henkind P. Rhabdomyosarcoma and late malignant melanoma of the orbit. Ophthalmology 1983; 90: 1258-60.

22 Shields JA. Cystic lesions of the orbit. In: Shields JA, ed. Diagnosis and management of orbital tumors. Philadelphia: Saunders 1989: 94-7.

23 Jakobiec FA, Bonanno PA, Sigelman J. Conjunctival adnexal cysts and dermoid. Arch Ophthalmol 1978; 96: 1404-9.

24 Shields JA, Augsburger JJ, Donoso LA. Orbital dermoid cys of conjunctival origin. Am f Ophthalmol 1986; 101: 726-9.

\title{
Late onset esotropia in monozygous twins
}

\author{
S Ahmed, J D H Young
}

\begin{abstract}
Monozygous twins who developed typical acute late onset esotropia are described. Neither had evidence of other neurological disease and both responded well to bimedial rectus muscle recessions. This twin presentation suggests a hereditary basis for the development of late onset esotropia in at least some cases. It provides further support for a policy of avoiding invasive CNS investigations in those patients who have binocular potential and are otherwise normal.

(Brf Ophthalmol 1993; 77: 189-191)
\end{abstract}

The sudden onset of strabismus in a previously normal child over the age of 4 is alarming to the parents. If there are no local aetiological factors it will also be of concern to the treating ophthalmologists aware that this might be the presenting sign of serious intracranial pathology. Typically strabismus secondary to neurological disease will be paralytic but concomitant strabismus is also a recognised presenting feature, especially of posterior fossa lesions. ${ }^{1}$

Concomitant esotropia not associated with any detectable neurological disorder may also occur in this age group. This has been described as late onset or normosensorial esotropia ${ }^{2}$ and is characterised by:

(1) An acute onset of esotropia with diplopia, in some cases initially intermittent for a short period.

(2) A potential for normal binocular function, demonstrable on orthoptic testing.

(3) No refractive error of relevance to the strabismus. 
(4) No associated neurological disorder identifiable.

As the majority of children who present with this condition do not subsequently develop neurological disease, it is difficult to know how far such patients should be investigated. We report a case of monozygous twins who developed acute late onset esotropia after their fourth birthday.

\section{Case reports}

CASE 1

Twin one presented at age 4 years and 2 months with sudden onset of left esotropia and diplopia, initially intermittent but increasing over a period of 1 week. There was no preceding illness and the child was generally well. One paternal uncle had had strabismus during childhood.

On examination the child had equal visual acuity in both eyes measured at $6 / 6$ with the Sheridan Gardiner single letter test. He preferred fixation with the right eye and on cover test had a left esotropia of 35 prism dioptres for both near and distance. There was no weakness of abduction or nystagmus in either eye. With a base out prism of 30 dioptres he could maintain binocular single vision. Anterior segment examination and funduscopy were unremarkable.

Following $1 \%$ cycloplegic retinoscopy glasses in the order of $\mathrm{RE}+2 \cdot 00 / 0 \cdot 25 \times 180^{\circ}, \mathrm{LE}+2 \cdot 00 /$ $+0.50 \times 180^{\circ}$ were provided. A full neurological examination at presentation and during follow up was normal. Wearing of glasses during this follow up period had virtually no effect on the esotropia. On the synoptophore he had fusion range of $20^{\circ}$ and stereopsis with bucket slides. A 10 base out Fresnel prism was applied to the right spectacle. This reduced the angle sufficiently for the patient to allow him to control the deviation and restore binocular single vision (BSV) confirmed with Bagolini's striated lenses and the Randot stereopsis test (stereo acuity at least 200 seconds of arc). Wearing the prism he was stable for 5 months and the angle remained unchanged. At this stage bimedial rectus muscle recession of $5 \mathrm{~mm}$ were carried out. Postoperatively he had a residual esophoria of 4 prism

Figure 1 Twin 1 on the left and twin 2 on the right. Both at age 7 .

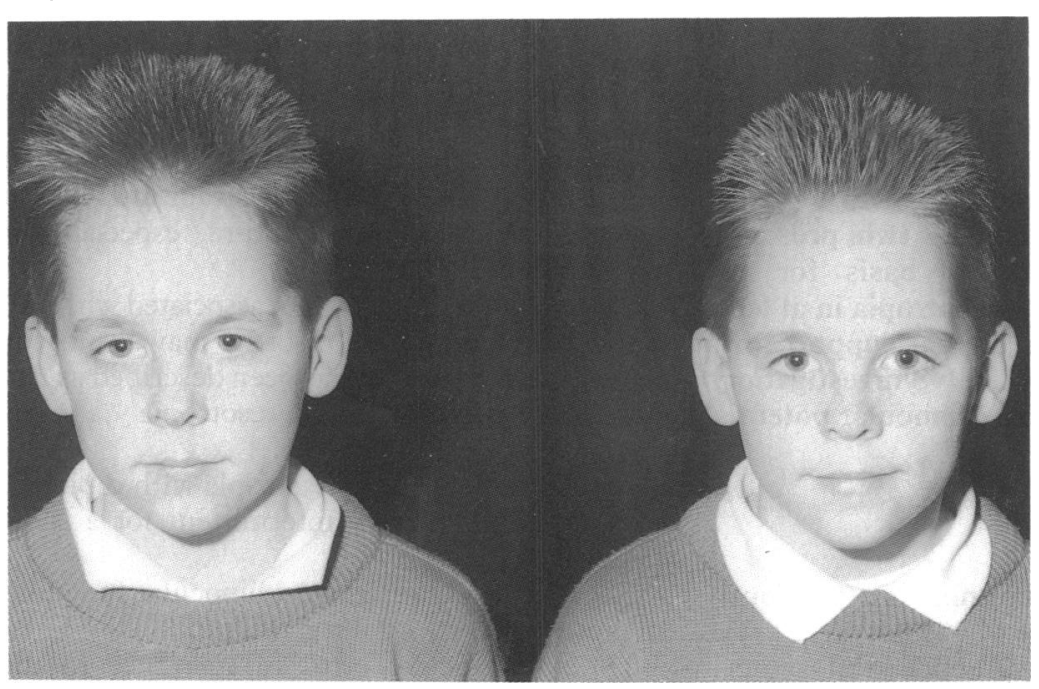

tion he continued to maintain BSV with acuities of 6/6 in both eyes (Fig 1). Throughout this period he did not develop any signs of systemic neurological disorder.

\section{CASE 2}

Twin two presented 14 months after his sibling at age 5 years 4 months with a similar history of sudden onset esotropia and diplopia. This was initially intermittent for a few days before becoming constant. On examination acuities were equal at $6 / 6$ on either side, he preferred fixation with the left eye and there was a manifest right estropia of 30 prism dioptres for both near and distance. Ocular movements were full and in particular there was no nystagmus or weakness of abduction. On the synoptophore he demonstrated binocular vision with a fusion range of $40^{\circ}$. His cycloplegic retinoscopy ( $1 \%$ cyclopentolate) was $+3.50 \mathrm{D}$ in both eyes. Corrective lenses of +1.75 DS for each eye were prescribed but at review the glasses had made no difference to the esotropia and the patient was constantly occluding his right eye because of the troublesome diplopia. A prism adaptation test with 25 prism dioptre base out restored BSV after 25 minutes. This was confirmed with Bagolini's striated lenses, and on the Randot stereopsis test he had a stereoacuity of at least 100 seconds of arc. He wore a 25 dioptre base out Fresnel prism applied to the right spectacle lens for 4 months. At that time, with his condition stable and the angle unchanged, bimedial rectus recession of $5 \mathrm{~mm}$ was performed.

Postoperatively he had 6 prism dioptres esophoria and restored BSV (Fig 1). No abnormal neurological signs were evident at presentation or during follow up.

\section{TWIN STUDIES}

Both twins were born by vaginal delivery under epidural anaesthesia at 38 weeks' gestation.

Twin 1 Birth weight: $2990 \mathrm{~g}$ required assisted forceps delivery.

Twin 2 Birth weight: 3090 g required assisted breech delivery.

The placenta was a monochorionic twin placenta. The mother had suffered from salpingitis during pregnancy and had been treated with metronidazole. She had also taken iron and folic acid supplements. Following birth, the twin development was normal in every respect. They fulfilled Nicholls and Bildrios criteria ${ }^{3}$ for monozygosity which gives a greater than $90 \%$ probability and takes into account similarities of sex, height, skin colour, hair, and eye colour and frequency of being mistaken by parents and friends. Their blood was also tested for the ABO system, RH system, Kell (K), Duffy, and the Lewis system. These were identical in both twins. Finally cytogenetic screening for five highly polymorphic single locus probes Ms8, 93, MSI, Ms31, and Ms43 was conducted. Each of these probes having a polymorphic content of greater than $80 \%$ was identical in the twins, giving the possibility of them not being mono- 
zygous as less than $0 \cdot 001$. On considering this in conjunction with other results monozygosity is almost certain.

\section{Comment}

Although strabismus has been reported in siblings and twins ${ }^{4-6}$ its most common form is during early infancy or childhood. ${ }^{7}$ To our knowledge there has been no previous case report of late onset concomitant esotropia in monozygous twins. However, one case of its occurrence in four members of the same family has been reported. ${ }^{8}$ From the comprehensive review by Burian and Millar' we could consider our case as type II late onset esotropia which is also known as Franceschetti type. They were not myopic as in type III (Bielchowsky) ${ }^{10}$ and nor was the onset caused by ocular occlusion as in type 1 (Swan). ${ }^{11}$

When a previously normal child presents with sudden onset of esotropia accompanied by diplopia after the age of 4 , it will be of concern to both the parents and the treating ophthalmologist, aware that this might be the presenting sign of serious intracranial pathology.

Williams and Hoyt ${ }^{1}$ reported a series of six such patients in whom tumours of the brain stem and cerebellum were subsequently detected. However in his series three of them had nystagmus and none of them demonstrated binocular potential. Four of the cases underwent strabismus surgery but none established ocular motor fusion. This is in sharp contrast to previously reported cases and in our twin case where binocular potential was always present and the patients had restored BSV following surgery. For example in a series of six patients reported by Clark et al, ${ }^{12}$ results of neuroradiological investigations including spinal tap and Tensilon tests were negative in all cases. All their patients showed binocular potential and did not develop suppression.
Since all the previous reports have been of individual cases this twin presentation may be of relevance to the aetiology of the condition, and the concern as to how far such cases should be investigated. Many authors have reported that heredity plays an important role in the control of eye movement and in the genesis of strabismus. ${ }^{1314}$ This twin presentation would point to such a hereditary basis for the development of late onset esotropia in at least some of the cases.

We feel that this provides further support for a policy of avoiding neuroradiological and other invasive investigations in children with isolated late onset esotropia who demonstrate the potential for binocular vision. By contrast patients with this condition who have additional neurological signs or who lack the potential for binocular vision must be further investigated.'

We thank Mrs Lynda Rose for typing the manuscript and Dr M Faed, University of Dundee, Pathology Department, for carrying out the cytogenetic studies.

1 Williams AS, Hoyt CS. Acute comitant esotropia in children with brain tumours. Arch Ophthalmol 1989; 107: 376-8

Min Jrain tumours. Arch Ophis and management of ocular motility disorders. Oxford: Blackwell, 1987: 107.

3 Nichols RC, Bildro WC. The diagnosis of twin zygosity. Acto Senet 1966; 16: 265

4 Scholssman A, Priestley BS. Role of heredity in aetiology and treatment of strabismus. Arch Ophthalmol 1952; 47: 1-20.

5 Lang J. Genetiseke Aspkte Bei Der Esotropie Eineiige Zeillinge. Klin Monatsbl Augenkeilkd 1990; 196: 275-8.

6 Bucci FA Jr, Catalano RA, Simon JW. Discordance of accommodative esotropia in monozygotic twins. Am $f$ Ophthalmol 1989; 107: 84-5.

7 Von Noorden GK. Binocular vision and ocular motility. 4th Ed. St Louis: Mosby, 1990: Chapter 14, 307.

8 Norbis AL, Malbran E. Concomitant esotropia of late onset pathological report in four cases in siblings. Br f Ophthalmol pathological report

9 Burian HM, Miller JE. Concomitant convergent strabismus with acute onset. Am f Ophthalmol 1958; 45: 55-64.

10 Bielchowsky A. Das Einwartsschielen der Myopen Ber Dtsch. Ophthalmol Ges 1922; 43: 245.

11 Swan KC. Esotropia following occlusion. Arch Ophthalmo 1947; 37: 444-5.

12 Clark AC, Nelson LB, Simon JW, Wagner R, Rubin SE Acute acquired concomitant esotropia. Br $\mathcal{f}$ Ophthalmol 1989; 73: 636-8.

13 Wardenburg PJ. Functional disorders of outer eye muscles. Genet Ophthalmol 1961; 2: 1009-60.

14 Francois J. Heredity in ophthalmology. St Louis: Mosby, 1961: 255 .

\author{
Abstract \\ Corneal intraepithelial neoplasia (CIN) is a \\ rare dysplastic process affecting mostly elderly \\ fair-skinned people. A variant of the disease \\ associated with contact lens wear was recently \\ described. The three cases reported here had a \\ history of contact lens wear together with \\ strong ultraviolet light exposure. These two
}

conditions may represent a serious risk factor for the development of CIN.

(Br F Ophthalmol 1993; 77: 191-192)

Corneal intraepithelial neoplasia (CIN) is a rare dysplastic process ranging from mild dysplasia to neoplasia ${ }^{1}$ affecting mostly elderly fair-skinned 